\title{
MSW ODOR QUANTIFICATION USING ELECTRONIC NOSE AND CHEMICAL ANALYZERS: RELATIVE EXPLORATION OF PREDICTION CAPABILITIES AND ROBUST MODEL DEVELOPMENT
}

\author{
Sharvari Deshmukh ${ }^{1,2}$, Hemant J.Purohit ${ }^{2}$, Atul N Vaidya ${ }^{2}$, Anne-Claude Romain ${ }^{1}$ \\ ${ }^{1}$ University of Liège, Arlon Campus Environment, Avenue de Longwy 185, 6700 Arlon, Belgium \\ ${ }^{2}$ CSIR- National Environmental Engineering Research Institute, Nagpur, India
}

\begin{abstract}
The work investigates the real-time measurements of municipal solid waste odors using both low-cost chemical sensor array (electronic nose) and chemical analyzers. The study aimed to develop mathematical models using multilinear regression for prediction of odor concentration using electronic nose and chemical analyzers respectively. Data collected over a period of five months (50 days) were simultaneously analyzed using electronic nose, chemical analyzers and olfactometer installed at Municipal Solid Waste site. Principal component analysis was carried out on sensors data to study the different sources and concentration levels of odors. The output of olfactometer was correlated with the response of sensor array and chemical analyzers using multilinear regression model. The prediction models developed for correlating electronic nose and olfactometer \& chemical analyzer with olfactometer helped to understand the usability of both electronic nose and chemical analyzer for odor concentration prediction. The results on these aspects are discussed in the paper.
\end{abstract}

Index Terms: Sensor array, chemical analyzers, dynamic olfactometer, Principal Component Analysis, Multi Linear regression, MSW

\section{INTRODUCTION}

Municipal solid waste (MSW) plants all around the world generate malodors [1]. These malodors need to be monitored in order to understand odor annoyance and to develop new odorless processes and treatment technologies [2]. An MSW plant was selected for the study. Two identical electronic nose systems (odor monitoring instrument) having six metal oxide sensor each were selected for this study. One of the electronic nose was station adjacent to nine chemical analyzer consisting of hydrogen sulfide analyzer, a methane analyzer, ammonia, benzene, toluene, ethylbenzene, limonene analyzer. The odors emitted from MSW site were continuously monitored using the two identical electronic nose systems and the nine analyzers for five months (50 days). Few odor samples were collected from the MSW site for simultaneous analysis using dynamic olfactometer and electronic nose system.

In the research paper, the results of the sensor array are analyzed using principal component analysis (PCA), to investigate the nature and events of odors occurring at the MSW site. Though very few odor samples were collected from the site for analysis using dynamic olfactometer, however, an attempt has been made to correlate the results of sensor array with dynamic olfactometer and also the output of chemical analyzer with dynamic olfactometer. The results on this aspect are discussed in the paper.

\section{MATERIALS AND METHODS \\ A. Electronic nose, Chemical analyzer setup and experimental procedure}

Two identical electronic nose systems equipped with six metal oxide sensor arrays having different selectivity and sensitivity (TGS 2602, TGS 2610, TGS 2611, TGS 2620, GGS 1330, TGS 2444) were installed at the MSW sites. The electronic nose system had sensors fitted in a cylindrical chamber made of PTFE and stainless steel. The volume of the sensor chamber was $200 \mathrm{~mL}$ with a capacity to fit in six sensors, a temperature probe, and a heater to maintain the internal temperature of the chamber at $50 \mathrm{oC}$. The sensor chamber's inlet and outlet are respectively centered on the inferior and superior sides of the cylinder-forming size, where sensors are forming a circle perpendicular to the gas flow. An adjustable flow pump regulated at a flow rate of $250 \mathrm{~mL}$ min-1 is placed after the sensor chamber. The acquisition of sensor signals and controlling of hardware was carried out using software developed in LabView (NI instrument, USA). The sensor's resistance was measured every $10 \mathrm{~s}$, averaged out in 1 minute and stored in local memory. Out of the nine analyzers, the response of three chemical analyzers used at site i.e FID for $\mathrm{CH} 4$, chemiluminescence for $\mathrm{NH} 3$ and UV fluorescence for $\mathrm{H} 2 \mathrm{~S}$ had prominent results and were further used for analysis. The analyzers' responses are directly recorded either in ppm or in $\mu \mathrm{g} / \mathrm{m}^{3}$.

\section{A. Dynamic Olfactometry}

Dynamic olfactometry according to the EN13725 is a common and traditional technique for quantitative analysis of odor emissions. It allows measuring the total effect of the odor on human perception using human nose as a detector. The polluted sample is diluted with pure air/ odorless air to reduce the odor concentration to its detection threshold. A series of diluted samples are presented to the panelist in descending order. This procedure is followed until the panelists are unable to distinguish between odorous and odor free sample [3]. This is termed as odor detection threshold and defined as $1 \mathrm{ouE} / \mathrm{m} 3$ of odor concentration. The analysis was performed using an Odile olfactometer (Odotech, Canada) according to EN 13725:2003 at the laboratory of the University of 
Liége. The different dilutions of the odor were presented to a panel of 6 trained panelists by a decreasing step sequence in geometric series of factor 1.58 .

\section{Field-based investigation}

The MSW samples were analyzed and measured on site using two identical electronic nose system and three chemical analyzers. The samples were collected from major source points and analyzed. Odor gas is collected in a polymer bag (Nalophan) placed in a sealed barrel maintained under negative pressure by a vacuum pump. The odors are analyzed within 08 hours after the sampling. The odor concentration range at different source areas is provided in Table 1

Table 1: Range of odor concentration at MSW site

\begin{tabular}{|c|c|c|}
\hline & Minimum & Maximum \\
\hline $\begin{array}{c}\text { MSW Odor } \\
\text { concentration }\left(\mathrm{ou}_{\mathrm{E}} / \mathrm{m}^{3}\right)\end{array}$ & $19 \mathrm{ou}_{\mathrm{E}} / \mathrm{m}^{3}$ & $499 \mathrm{ou}_{\mathrm{E}} / \mathrm{m}^{3}$ \\
\hline
\end{tabular}

\section{III.RESULTS AND DISCUSSION}

The sensor array and chemical analyzers were exposed to MSW odors for 50 days. The response of sensor thus obtained from sources on the MSW site was subjected to PCA. The first (PC1) and the second component (PC2) represented $96 \%$ of the total data variations. The obtained results of PCA reveal that selected sensors are correlated and useful in measuring the odor present at the MSW site. The data analysis was carried out in Minitab 17 software [4, 5]. Fig. 1 shows that the sensor array could differentiate between types of odor sources.

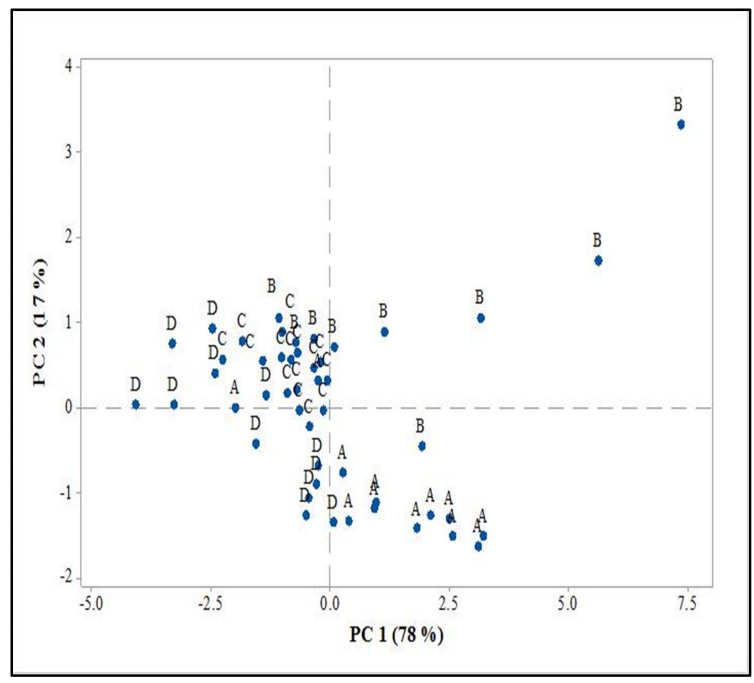

A: concentrations of $\mathrm{CH}_{4}, \mathrm{NH}_{3}, \mathrm{H}_{2} \mathrm{~S}$ all present and high $\mathrm{B}: \mathrm{NH}_{3}$ in very high concentration $\mathrm{C}: \mathrm{NH}_{3}$ Higher than $\mathrm{H}_{2} \mathrm{~S}$ and $\mathrm{CH}_{4} \mathrm{D}: \mathrm{NH}_{3}, \mathrm{H}_{2} \mathrm{~S}, \mathrm{CH}_{4}$ all very low

Figure 1. PCA clusters of sensor array data for different odors at MSW site (sensor's resistance in kohm)

Though a large amount of data was collected for an electronic nose system and chemical analyzer, a relatively lower amount of data was collected using dynamic olfactometer. Only 20 data sets were collected for study using dynamic olfactometer. The details of the same are provided in Table 1. The results of chemical analyser to the odor present at MSW site is as shown in Figure 2.

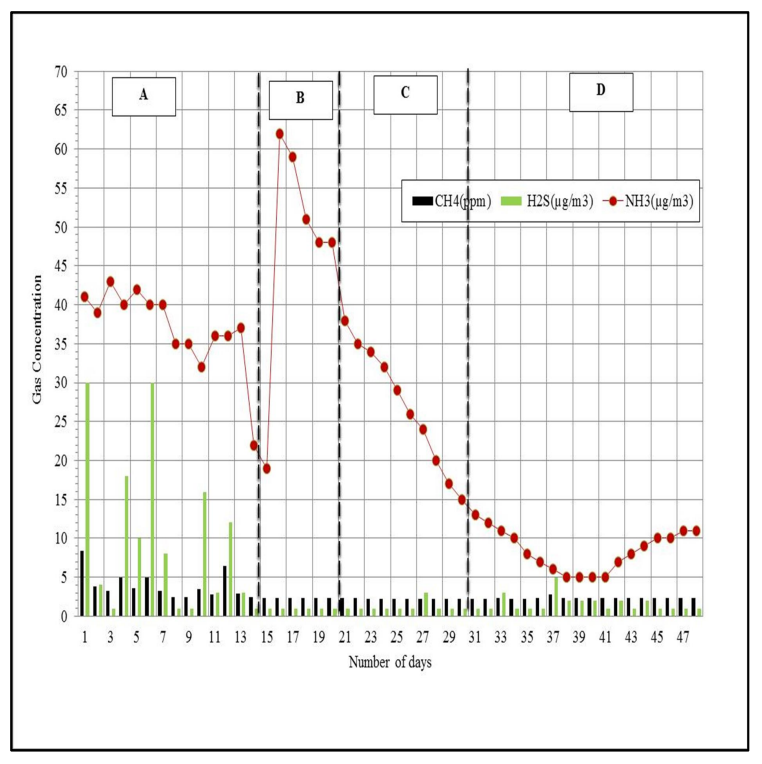

Figure 2. . Result of chemical analyzer for MSW site

Out of the 20 datasets, only 6 were having odor concentration detectable by electronic nose system (Lower Odor Detection i.e. LOD of current electronic nose $110 \mathrm{ou}_{\mathrm{E}} / \mathrm{m}^{3}$ derived based on experiments). The results of these 6 datasets consisting of sensor array response and odor concentration were subjected to Monte Carlo simulation. The Monte Carlo simulation was used to generate more data sets to develop a correlation model. Based on the Monte Carlo simulation 50 datasets were generated which were further analyzed using D-Optimality [4,5]. The Doptimality generated 25 datasets. These 25 data sets consisting the response of sensor array and dynamic olfactometer were correlated using Multi Linear Regression (MLR). Multiple linear regression (MLR) models the relationship between two or more independent variables and a response variable by fitting a linear equation to observed data. Every value of the independent variable $\mathrm{x}$ is associated with a value of the dependent variable $y$. The results obtained by testing samples collected at the industrial site by using electronic nose and field olfactometer were used to develop an empirical model using MLR. The sensor's response expressed in resistance (Kohm) as input to the model and the olfactometer reading acted as the output of the model. The application of MLR resulted in the following equation

$O C=17.8+5.17 * S_{1}-0.84 * S_{2}+9.28 * S_{3}-$

$8.21 * S_{4}+10.797 S_{5}-0.990 * S_{6}$

where S1,S2,S3,S4,S5,S6 were six different sensors TGS 2602, TGS 2610, TGS 2611, TGS 2620, GGS 1330, TGS 2444 respectively and OC the predicted 
odor concentration. The p-values $(\alpha=0.05)$ were used as a tool to check the significance of each of the coefficients. The smaller the magnitude of $p$, more significant is the corresponding coefficient. The model adequacies were checked by $R^{2}$. A model with large $R^{2}$ is considered to be a good model. The developed model had $R^{2}$ of 0.96 . The $R_{\text {pred }}^{2}$ value of the model represents how successfully the model fits the data and for the developed model it was found to be 0.91 . The high $R^{2}$ for the developed model could explain the variations present in the independent variables. Whereas, $R_{\text {pred }}^{2}$ which represents the ability of the derived model to predict the output for unknown samples was also found to be high for the models. Fisher's variance ratio $F$-value is calculated as a ratio of mean square regression and mean square residual. It is a measure of variance in the data about the mean. The lack of fit and error has been well explained in reference [4] and [5]. Table 2 represents all the model values. Further, cross-validation of the obtained results was carried out using leave one out methodology. The cross validation resulted in an error of $30.04 \%$.

Table 2. Analysis of variance for MLR (sensor array)

\begin{tabular}{|l|l|l|l|l|l|}
\hline Source & DF & $\begin{array}{l}\text { Sum of } \\
\text { Squares } \\
(\mathrm{SS})\end{array}$ & $\begin{array}{l}\text { Mean } \\
\text { Squares } \\
(\mathrm{MS})\end{array}$ & $\mathrm{F}$ & $\mathrm{P}$ \\
\hline $\begin{array}{l}\text { Model } \\
\text { (Linear) }\end{array}$ & 6 & 135238 & 22540 & 50.03 & 0.000 \\
\hline S1 & 1 & 6028 & 6028 & 13.38 & 0.004 \\
\hline S2 & 1 & 66 & 66 & 0.15 & 0.709 \\
\hline S3 & 1 & 9365 & 9365 & 20.79 & 0.001 \\
\hline S4 & 1 & 23637 & 23637 & 52.46 & 0.000 \\
\hline S5 & 1 & 107052 & 107052 & 237.60 & 0.000 \\
\hline S6 & 1 & 4863 & 4863 & 10.79 & 0,007 \\
\hline Error & 11 & 4956 & 451 & & \\
\hline $\begin{array}{l}\text { Lack of } \\
\text { fit }\end{array}$ & 1 & 4956 & 4956 & 2.7736 & 0.000 \\
\hline $\begin{array}{l}\text { Pure } \\
\text { Error }\end{array}$ & 10 & 0 & 0 & & \\
\hline Total & 17 & 140194 & & & \\
\hline
\end{tabular}

Since the two electronic nose systems were identical the above developed was applied to second electronic nose system and odor concentrations observed at the MSW site were calculated. This electronic nose system was coupled with three analyzers (H2S, NH3, CH4). As such the odor concentration calculated using sensor array system were used to develop a correlation model with three chemical analyzers and odor concentration using MLR. The application of MLR between analyzers and odor concentration resulted in the following equation

$O C=287.7+0.58 * U+0.278 * V+0.73 * W(2)$

where $\mathrm{U}, \mathrm{V}, \mathrm{W}$ were three different analyzers and OC the predicted odor concentration. The developed model had an $R^{2}$ value of 0.59 and $R_{\text {pred }}^{2}$ value of 0.46 . Table 2 represents all the model values.
Table 3: Analysis of variance for MLR (chemical analyser)

\begin{tabular}{llllll}
\hline Source & DF & SS & MS & F & P \\
\hline $\begin{array}{l}\text { Model } \\
\text { (Linear) }\end{array}$ & 3 & 5919.9 & 1973.29 & 15.13 & 0.000 \\
$\mathrm{U}$ & 1 & 0.9 & 0.85 & 0.01 & 0.936 \\
$\mathrm{~V}$ & 1 & 11.2 & 11.19 & 0.09 & 0.771 \\
$\mathrm{~W}$ & 1 & 4456.6 & 4456.58 & 34.17 & 0.000 \\
Error & 39 & 5086.6 & 130.43 & & \\
Total & 42 & 11006.5 & & & \\
\hline
\end{tabular}

The relatively low value of $\mathrm{R}^{2}$ value model developed for analyzers (0.59) compared that obtained for sensor array model $\left(\mathrm{R}^{2} 0.96\right)$ suggested that there were others than $\mathrm{H}_{2} \mathrm{~S}$, Methane, and $\mathrm{NH}_{3}$, that were captured by sensor array more appropriately.

\section{CONCLUSION}

This paper presents some of the results of a continuous ongoing study on an MSW site to monitor the odor sources combining the results of sensor array and analyzers. The results of sensor array were analyzed using PCA showing the selected sensor array could effectively distinguish different odors. Based on the very few results of olfactometer a correlation was established between sensor array \& olfactometer and that of the chemical analyzer and olfactometer data. The results suggest that sensor array could more effectively capture the odor profile compare to the analyzers. Sensor array thus could provide a low-cost solution to monitor odor at huge sites like MSW. However, the further study needs to carry out to validate the results.

\section{ACKNOWLEDGEMENT}

The author (SD) is thankful to SERB-DST for the award of "SERB Overseas postdoc fellowship". The authors are thankful to Dr. Rakesh Kumar, Director, CSIR- NEERI and A. CORHAY, Rector University de Liege. The authors want specially thank the "Cellule Qualite de l'Air" de l'ISSeP for the availability of their analysers and the diffusion of their data.

\section{References}

[1] Anne-Claude Romain, Noémie Molitor, Gilles Adam, Emerance Bietlot, Catherine Collard, Comparison "Low cost chemical sensors - Analytical instruments" for odor monitoring in a municipal waste plant, CHEMICAL ENGINEERING TRANSACTIONS

[2] S. De Vito, E. Massera, M. Piga, L. Martinotto, G. Di Francia, On field calibration of an electronic nose for benzene estimation in an urban pollution monitoring scenario, Sensors and Actuators B: Chemical 129, (2), 2008

[3] EN 13725-Air quality - determination of odor concentration by dynamic olfactometry, 2003-04-01

[4] P. Mathews, "Design of Experiments with MINITAB," Pearson Education Press, Upper Saddle River, 2005.

[5] D. C. Montgomery, "Design and Analysis of Experiments," 5th Edition, Wiley, New York, 2011 